\title{
Highly sensitive troponin $t$ (hstnt) profile for outcome prediction after cardiac surgery
}

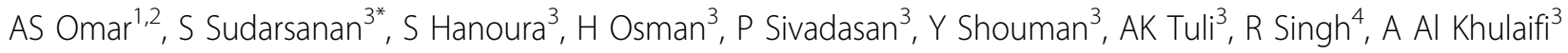 \\ From ESICM LIVES 2015 \\ Berlin, Germany. 3-7 October 2015
}

\section{Introduction}

Changes in cardiac mediators remain a subject of research interest. Instantly obtainable biomarkers that are performed routinely, are inexpensive and are characterized by linkages to outcome in cardiac surgery settings are optimum. Post-operative conventional cardiac troponins are linked to short- and middle-length outcomes [1] but highly sensitive troponin $\mathrm{T}$ (hsTnT) has not been extensively evaluated in the same settings.

\section{Objectives}

To assess the ability of hsTnT to prognosticate outcomes in cardiac surgery.

\section{Methods}

We conducted a single-center, prospective observational study over 2 years. We analyzed the data from all patients who underwent cardiac surgery. We recruited 413 patients with a mean age of $54.9 \pm 10.9$ years. The patients were divided into two groups based on hsTnT level, which is analogous to creatine kinase MB (CK$\mathrm{MB}$ ) and indicates myocardial injury (with and without myocardial infarction) [2]. The receiver operator curve (ROC) was used to determine this relation, retrieving a level of $2309 \mathrm{ng} / \mathrm{L}$ and showing an $80 \%$ sensitivity and an $86 \%$ specificity (figure). We used a $t$-test to compare variables and multivariate analysis was conducted for significant variables.

\section{Results}

Two groups (group A (372 patients) and group B (41 patients)) were both matched for age, body mass index, diabetes mellitus association, serum creatinine, Euroscore, aortic cross clamp and cardiopulmonary bypass

${ }_{3}^{3}$ Hamad Medical Corporation, Cardiothoracic Surgery-Heart Hospital, Doha, Qatar

Full list of author information is available at the end of the article

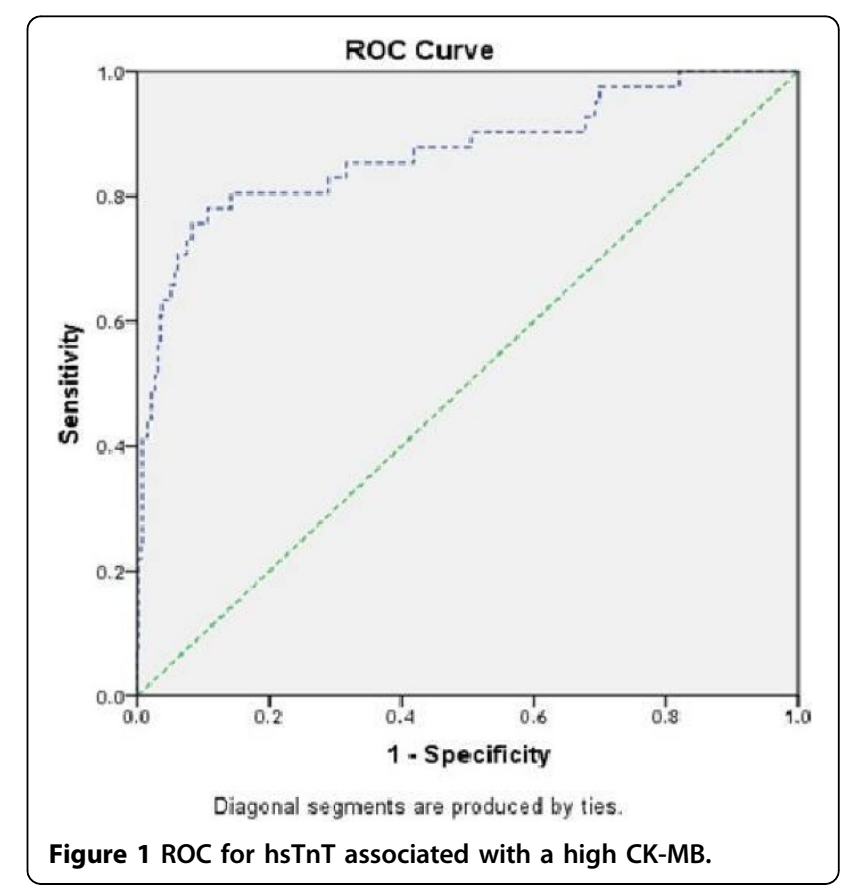

time, and total length of anesthesia. Patients with hsTnT levels of $2309 \mathrm{ng} / \mathrm{L}$ or lower had a better outcome in terms of inotropes need, lengths of ventilation (LOV), ICU and hospital stay, and post-operative complications. Multivariate analysis revealed significant relations of the given level with operative emergency $(\mathrm{p}=$ 0.001 ); the level was a predictor for a longer duration of mechanical ventilation $(\mathrm{p}=0.01)$ and post-operative atrial fibrillation (POAF) $(\mathrm{p}=0.003)$ (Table 1). Moreover, 9 patients $(21.9 \%)$ in group $B$ had perioperative myocardial infarctions.

\section{Conclusions}

Outcome prediction in cardiac surgery in terms of PMI, LOV and POAF could be enhanced by using a set level 
Table 1. Multivariate logistic regression for hsTnT

\begin{tabular}{llll}
\hline Variable & Adjusted OR & $\mathbf{9 5 \% ~ C l}$ & P-Value \\
\hline Operation emergency & 10.21 & $2.5-41.3$ & 0.001 \\
\hline LOV & 1.01 & $1.00-1.02$ & 0.01 \\
\hline AKI & 0.84 & $0.32-2.20$ & 0.72 \\
\hline POAF & 4.79 & $1.7-13.5$ & 0.003 \\
\hline Mortality & 3.71 & $0.4-32.9$ & 0.24 \\
\hline
\end{tabular}

$\mathrm{Cl}$ : confidence interval; LOV: length of ventilation; AKI: acute kidney injury; POAF: post-operative atrial fibrillation

of hsTnT; this profile serves as a powerful laboratory marker to identify high-risk patients.

\section{Grant Acknowledgment}

We thank all members of cardiothoracic surgery department and the medical research center of Hamad medical corporation.

\section{Authors' details}

${ }^{1}$ Hamad Medical Corporation, Doha, Qatar. ${ }^{2}$ Faculty of Medicine, Critical Care Medicine, Beni_Suef, Egypt. ${ }^{3}$ Hamad Medical Corporation, Cardiothoracic Surgery-Heart Hospital, Doha, Qatar. ${ }^{4}$ Hamad Medical Corporation, Medical Research Center, Biomedical Statistics, Doha, Qatar.

Published: 1 October 2015

\section{References}

1. Buse GAL, Koller MT, Grapow M, et al: The prognostic value of troponin release after adult cardiac surgery. A meta-analysis. Eur J Cardiothorac Surg 2010, 37(2):399-406.

2. Thygesen K, Alpert JS, Jaffe, et al: Joint ESC/ACCF/AHA/WHF Task Force for the Universal Definition of Myocardial Third universal definition of myocardial infarction. Eur Heart J 2012, 33(20):2551-67.

doi:10.1186/2197-425X-3-S1-A108

Cite this article as: Omar et al:: Highly sensitive troponin t (hstnt) profile for outcome prediction after cardiac surgery. Intensive Care Medicine Experimental 2015 3(Suppl 1):A108.

\section{Submit your manuscript to a SpringerOpen ${ }^{\circ}$ journal and benefit from:}

- Convenient online submission

- Rigorous peer review

- Immediate publication on acceptance

- Open access: articles freely available online

- High visibility within the field

- Retaining the copyright to your article

Submit your next manuscript at $>$ springeropen.com 